\title{
Dormant micro arteriovenous malformations lead to recurrent cerebral haemorrhage
}

\author{
Jun Cai ${ }^{1}$, Hao Lin' ${ }^{1}$, Shaoxue Li ${ }^{1}$, Zhimin Zou' , Yanting Zhang ${ }^{1}$, Shiwan Liu' ${ }^{1}$ Xin Chen ${ }^{2}$ and Xiaoxin Bai ${ }^{*}$
}

\begin{abstract}
Introduction: Some micro arteriovenous malformations (AVMs) located in deep brain are undetectable. How to choose a proper timing to detect these AVMs remains unclear.

Case description: A 21-year-old male patient was admitted to our center for intraventricular haematoma. Digital subtraction angiographies (DSAs) were performed one week and one month respectively after his haemorrhage, but no positive results were obtained. The patient was hospitalized for re-haemorrhage six years later. A micro AVM with two diffused niduses was detected and embolised three months after his re-haemorrhage. The patient recovered without any neurological deficit.
\end{abstract}

Discussion and evaluation: Compressive effects of haematoma and spontaneous obliteration of AVMs might play pivotal roles in negative DSA results.

Conclusions: Strategic and timely use of DSA could identify some dormant re-haemorrhagic AVMs.

Keywords: Arteriovenous malformations, Cerebral haemorrhage, Digital subtraction angiography

\section{Introduction}

Rupture of brain arteriovenous malformations (AVMs) is a leading cause of cerebral haemorrhage in children and young adults, with 1.4-4.67 \% of AVM patients developing cerebral haemorrhage each year (da Costa et al. 2009; Gross and Du 2013; van Beijnum et al. 2011). Some micro AVMs with unconspicuous feeding arteries and single draining veins are located in deep brain and it's difficult to diagnose such AVMs. Moreover, these dormant and re-haemorrhagic AVMs usually lead to high mortality and morbidity.

\section{Case report}

A 21-year-old male patient was admitted to our center with acute headache and loss of consciousness in 2009. Intraventricular haematoma was confirmed by computed

\footnotetext{
*Correspondence: bxxzjj@163.com; baixx_gdhtcm@163.com

${ }^{1}$ Department of Neurosurgery, Hospital of Guangzhou University Mega Center, Guangdong Provincial Hospital of Chinese Medicine, Guangzhou 510006, China

Full list of author information is available at the end of the article
}

tomography (CT) scan (Fig. 1A-a, b). The patient recovered consciousness after ventricular drainage and the removal of intraventricular haematoma (Fig. 1A-c-f). One week after the haemorrhage, the patient was diagnosed with digital subtraction angiography (DSA) for the causes of haemorrhage, but no positive results were obtained (Fig. 2A-a). DSA was repeated 1 month later with a micro-catheter to obtain super-selective angiograpy of micro cerebral arteries, including posterior choroidal arteries. However, no cerebrovascular disease was identified (Fig. 2A-b; Additional file 1). The patient was discharged 1 month after his haemorrhage without any measurable neurological deficit.

In 2015, the patient was hospitalized in our center again for haemorrhage in splenium corporis callosi (Fig. 1B). He had headache, lost consciousness, and experienced plegia and aphasia. DSA was performed 3 days after haemorrhage. No sign of abnormal cerebral angioarchitecture was observed (Fig. 2A-c). Three months later, the patient was examined with DSA again after the cerebral haemorrhage was assimilated. A micro AVM 

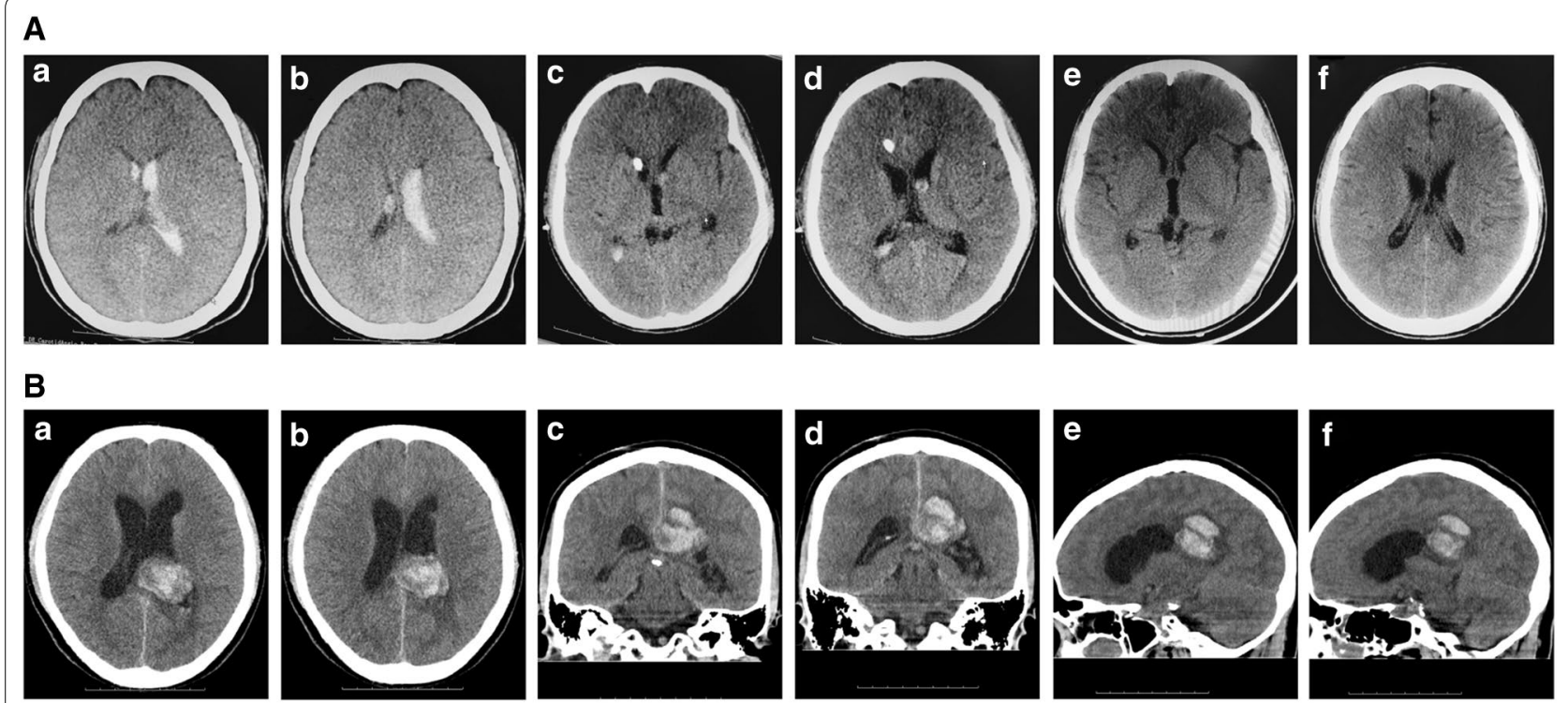

Fig. 1 CT images showed morphologies of cerebral haemorrhage. The preceding haemorrhage was located in the ventricle $(\mathbf{A}-a, b)$. Ventricular drainage was employed to remove the intraventricular haematoma $(\mathbf{A}-c-f)$. 3D CT images showed the morphology of recurrent cerebral haemorrhage (B- $a-f)$. B Expansile ventricles
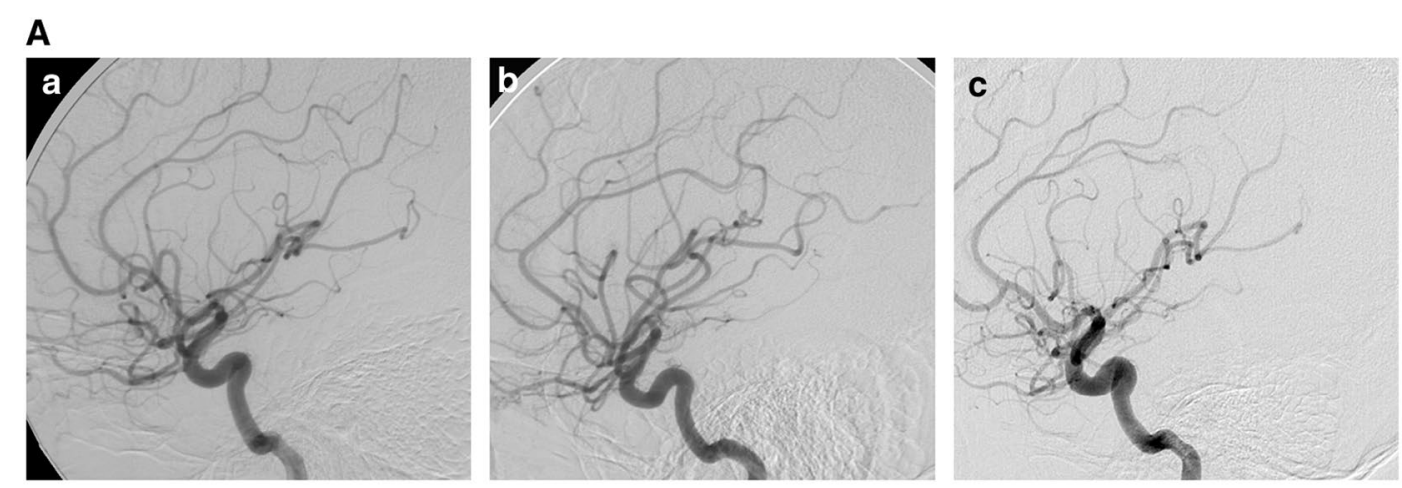

B
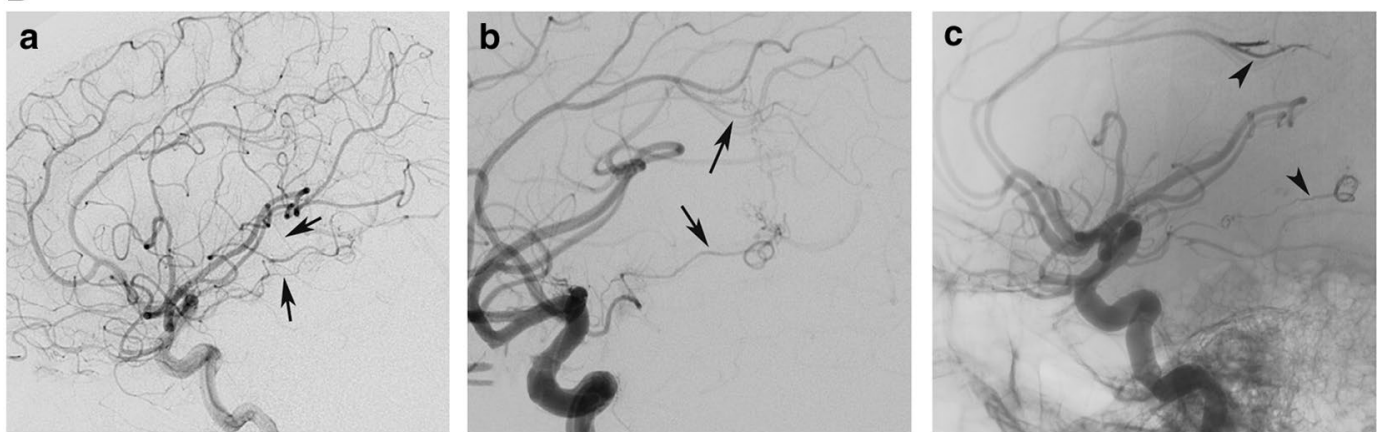

Fig. 2 DSA images displayed the left ICA angioarchitecture from various examinations. Two micro AVMs, which were identified in the last examination (B- $a-c)$, were not diagnosed in the first three DSA examinations $(\mathbf{A}-a-c)$. Arrows pointed at the feeding arteries of AVMs before embolization $(\mathbf{B}-a, b)$; and arrowheads showed the embolised feeding arteries after embolization (B-c) 
with two non-compact niduses in different parts of the brain was identified. One of the niduses was supplied by an arteriole of the left callosomarginal artery and the other by a branch of the left anterior choroidal artery. These two micro niduses were drained via the same veinlet, one of the thalamic veins, to the great cerebral vein (Fig. 2B-a, b). The feeding arteries of these two niduses were embolised with $0.5 \mathrm{ml}$ Onyx (Covidien, Irvine, CA, USA; Fig. 2B-c). In the end, the patient was discharged without any neurological deficit.

\section{Discussion}

The annual haemorrhage incidence rate of multiple AVMs was $6.7 \%$, higher than that of the overall haemorrhage (Boone et al. 2016). In this case, two micro AVMs were diagnosed in different parts of the brain with common drainage in the dorsal thalamus (Fig. 2B-a, b). With the CT images of the haemorrhage morphologies (Figs. 1A-a, b, 2B), we believed that the lower AVM was associated with the first haemorrhage while the upper AVM was associated with the second haemorrhage. The incidence of AVM rupture depends on different risk factors, such as locations, volumes of nidus, AVM-associated aneurysms, sex, treatment modalities and draining veins (da Costa et al. 2009; Gross and Du 2013; Rutledge et al. 2014). It was reported that micro AVMs with lowshunting had higher pressure in feeding arteries and greater incidence of haemorrhage (Brown et al. 1988; Kader et al. 1994), consistent with our finding that the micro AVM with two diffuse and spread niduses drained into the same vein. Therefore, micro AVMs located in the deep brain should be detected and removed.

Before the identification of this micro AVM, we obtained negative results in all three previous DSAs. Spontaneous obliteration of AVMs after haemorrhages likely played an important role in those negative DSA results (Goyal et al. 2015). Small size niduses with single draining vein were mostly apt to have spontaneous thrombosis (Abdulrauf et al. 1999). At the same time, the haematoma and its compressive effects on the draining veins aggravated the spontaneous obliteration (Abdulrauf et al. 1999; Krapf et al. 2001). In this study, spontaneous obliteration of AVMs could be re-canalized and should have been identified. However, early angiography at the setting of haematoma might hinder the diagnosis of micro AVMs (Alen et al. 2013). Therefore both a proper diagnosis time and a regular follow-up are needed to detect those dormant AVMs. We have suggested this patient to have DSA every three to 6 months after first cerebral haemorrhage. Unfortunately, he did not follow our suggestion. It's reported that some AVMs with spontaneous thrombosis were recanalized within 1 month to 5 years (Abdulrauf et al. 1999). Since we reported only one case here, it's hard to draw a conclusion regarding the timing of the follow-up DSA. More cases are required in future studies to get a firm conclusion. Recently, the patient followed our suggestion and took the follow-up DSA after AVM embolization. No recanalization or de novo AVM was diagnosed (Additional file 2).

Younger patients did have re-haemorrhage and AVMs recurred in the same region (Ali et al. 2003). It remained unknown why the micro AVM ruptured at different locations over years for the patient in this study. AVMs were traditionally regarded as congenial lesions but they could also be de novo (Bulsara et al. 2002). In addition, AVMs can change over time. For example, angiogenic factors and inflammatory factors can activate or de-activate AVMs respectively (Kim et al. 2009). AVM patient with spread nidus and haemorrhage in different locations over years as reported in this study was rare and more studies at the molecular level are needed to understand the mechanism in the future.

\section{Conclusions}

In summary, some micro, dormant, re-haemorrhagic AVMs located in deep brain can and should be diagnosed via DSA at an early time.

\section{Additional files}

Additional file 1. DSA images exhibited angiography of posterior cerebral circulation and micro-angiography of posterior choroidal arteries. Macro-angiographies of posterior circulation were displayed in panels $\mathbf{a}$ and $\mathbf{b}$. Axial (c,e) and sagittal (d,f) views of micro-angiographies in left (c,d) and right $(\mathbf{e}, \mathbf{f})$ posterior choroidal arteries showed no abnormal angioarchitecture.

Additional file 2. DSA images displayed cerebral angiography changes after AVM embolization. The images were taken 5 months after interventional embolization during the patient's follow-up examination. No re-canalization or de novo AVM was detected.

\section{Authors' contributions}

$J C$ performed interventional surgery and medical management of the patient, and drafted the manuscript. HL performed interventional surgery and assisted in manuscript preparation. SL and ZZ participated and assisted in the digital subtraction angiography. $Y Z$ and SL participated in the rehabilitation of the patient. XC collated the image data. XB supervised whole management of the patient and performed interventional surgery. All authors read and approved the final manuscript.

\section{Author details \\ ${ }^{1}$ Department of Neurosurgery, Hospital of Guangzhou University Mega Center, Guangdong Provincial Hospital of Chinese Medicine, Guang- zhou 510006, China. ${ }^{2}$ Department of Radiology, Guangdong Provincial Hospital of Chinese Medicine, Guangzhou 510120, China.}

\section{Acknowledgements}

We thank Dr. Shuangxi Sun for the imaging data collection. This study was supported by the National Natural Science Foundation of China (NSFC No. 81301013) and the Guangdong Natural Science Foundation of China (No. S2013040013591). 


\section{Competing interests}

All authors declare that they had no competing interests.

\section{Patient consent}

The patient and his parents have consented to the submission of this case report for publication.

Received: 27 January 2016 Accepted: 17 June 2016

Published online: 11 July 2016

\section{References}

Abdulrauf SI, Malik GM, Awad IA (1999) Spontaneous angiographic obliteration of cerebral arteriovenous malformations. Neurosurgery 44:280-287

\section{(discussion 287-8)}

Alen JF, Lagares A, Paredes I, Campollo J, Navia P, Ramos A, Lobato RD (2013) Cerebral microarteriovenous malformations: a series of 28 cases. J Neurosurg 119:594-602

Ali MJ, Bendok BR, Rosenblatt S, Rose JE, Getch CC, Batjer HH (2003) Recurrence of pediatric cerebral arteriovenous malformations after angiographically documented resection. Pediatr Neurosurg 39:32-38

Boone CE, Caplan JM, Yang W, Ye X, Colby GP, Coon AL, Tamargo RJ, Huang $J$ (2016) Hemorrhage risk and clinical features of multiple intracranial arteriovenous malformations. J Clin Neurosci 23:51-57

Brown RD Jr, Wiebers DO, Forbes G, O'Fallon WM, Piepgras DG, Marsh WR Maciunas RJ (1988) The natural history of unruptured intracranial arteriovenous malformations. J Neurosurg 68:352-357
Bulsara KR, Alexander MJ, Villavicencio AT, Graffagnino C (2002) De novo cerebral arteriovenous malformation: case report. Neurosurgery 50:11371140 (discussion 1140-1)

da Costa L, Wallace MC, Ter Brugge KG, O'Kelly C, Willinsky RA, Tymianski M (2009) The natural history and predictive features of hemorrhage from brain arteriovenous malformations. Stroke 40:100-105

Goyal N, Hoit D, Elijovich L (2015) Spontaneous thrombosis of a ruptured brain arteriovenous malformation: the argument for early conservative management. Interv Neurol 3:122-128

Gross BA, Du R (2013) Natural history of cerebral arteriovenous malformations: a meta-analysis. J Neurosurg 118:437-443

Kader A, Young WL, Pile-Spellman J, Mast H, Sciacca RR, Mohr JP, Stein BM (1994) The influence of hemodynamic and anatomic factors on hemorrhage from cerebral arteriovenous malformations. Neurosurgery 34:801-807 (discussion 807-8)

Kim H, Pawlikowska L, Chen Y, Su H, Yang GY, Young WL (2009) Brain arteriovenous malformation biology relevant to hemorrhage and implication for therapeutic development. Stroke 40:S95-97

Krapf H, Siekmann R, Freudenstein D, Kuker W, Skalej M (2001) Spontaneous occlusion of a cerebral arteriovenous malformation: angiography and MR imaging follow-up and review of the literature. AJNR Am J Neuroradiol 22:1556-1560

Rutledge WC, Ko NU, Lawton MT, Kim H (2014) Hemorrhage rates and risk factors in the natural history course of brain arteriovenous malformations. Transl Stroke Res 5:538-542

van Beijnum J, van der Worp HB, Buis DR, Al-Shahi Salman R, Kappelle LJ, Rinke GJ, van der Sprenkel JW, Vandertop WP, Algra A, Klijn CJ (2011) Treatment of brain arteriovenous malformations: a systematic review and metaanalysis. JAMA 306:2011-2019

\section{Submit your manuscript to a SpringerOpen ${ }^{\circ}$ journal and benefit from:}

- Convenient online submission

- Rigorous peer review

- Immediate publication on acceptance

- Open access: articles freely available online

- High visibility within the field

- Retaining the copyright to your article 